\title{
La creatividad en la vida
}

\section{Creativity in Lif}

\author{
José Alberto Rubí Barquero ${ }^{1}$ \\ Escuela de Filosofía \\ Universidad Nacional de Costa Rica \\ Heredia, Costa Rica \\ joserubi54@yahoo.com
}

Recibido 10 de noviembre de 2010 • Aceptado 09 de marzo de 2011

\begin{abstract}
Resumen. En este artículo desarrollo la idea de que la creatividad no está restringida al ámbito del arte, como suele creerse, ya que el arte es solo una expresión de la creatividad, que los humanos hacemos muchísimas cosas más que requieren de creatividad y que ni siquiera la creatividad es un atributo de los humanos pues a partir de ciertos niveles vitales se pueden observar conductas en los seres vivos que implican grados diferentes de cognición estética.
\end{abstract}

Palabras claves. Creatividad, estética, arte, cognición, música, literatura, cine.

Abstract. In this paper, the author explains the following ideas: that creativity is not restricted to the sphere of art, as it is usually considered, since art is just an expression of creativity; that people do many things that require creativity; and that not even creativity is an attribute of humans, since, from certain critical levels, we may observe behaviors in living beings that involve different degrees of aesthetic cognition.

Keywords. Creativity, aesthetic, art, cognition, music, literature, cinematography.

\section{Un día especial}

En los días en que yo entré a la Universidad de Costa Rica no existían las limitaciones de ingreso a las carreras que existen actualmente. Uno podía, entonces, darse el lujo, los primeros años, de andar de carrera en carrera hasta encontrar la de su gusto. De no ser así, posiblemente hubiese desertado de la universidad y mi historia sería diferente. La anécdota que voy a referir ocurrió cuando ya me había ubicado en la carrera de Filosofía y mi paso por Matemáticas e Ingeniería Civil quedaba en el pasado.

Doctor en Educación y Licenciado en Filosofía. Es profesor en la Escuela de Filosofía de la Universidad Nacional de Costa Rica. 
Ese día, al salir de una de las clases, me fui platicando con un compañero con el que ya tenía cierta amistad y al cual comenzaba a admirar porque a pesar de que teníamos la misma edad, era evidente que él se tomaba más en serio las cuestiones filosóficas y que había leído montones de libros que yo ni siquiera sabía que existían. Caminábamos hacia la soda que estaba en una esquina frente a la Universidad, la soda Guevara, y al pasar por el edificio de Ciencias y Letras, de un amplificador que colgaba de una de sus paredes salía una

Había leído montones de libros

que yo ni siquiera sabía que existían música de la que yo solo podía decir que era música clásica y continuar el camino sin prestarle mayor atención. Pero ese día mi compañero, posiblemente sin darse cuenta de lo que estaba provocando en mí, con solo que me dijo lo mucho que le gustaba esa melodía y el aprecio que sentía por su autor, al que llamó por su nombre en un tono que no dejaba ninguna duda de que estaba familiarizado con su música, me impresionó. En mis veinte años de vida yo nunca había oído a una persona joven hablando en esos términos acerca de esa música. El resultado fue que a partir de ahí se despertó en mí el más genuino interés por la música clásica y no pasaron muchos días para que me hiciera asiduo oyente de la emisora de radio de la Universidad de Costa Rica, que tenía en su programación suficientes espacios dedicados a dicha música.

Mi amistad con este compañero iba creciendo día con día y una tarde en la que otra vez caminábamos juntos por los senderos de la Universidad, ya cuando nos disponíamos a despedirnos, tomó uno de los libros que traía consigo y me lo prestó. Era una novela de Hesse ${ }^{2}$ (1978), un autor nuevo para mí, dado que para ese entonces yo solo había leído lo que de literatura se leía en el colegio y a la manera como se lee en el colegio, es decir, prácticamente por obligación, así que el goce estético cognoscitivo proveniente de las lecturas literarias del que podía hablar mi amigo, para mí no significaba gran cosa.

Cuando se teme a alguien es porque a ese alguien le hemos concedido poder sobre nosotros.

- Demian, Cap. 2 (Max Demian) (Hesse, 1978, p. 55)

Solo cuando comencé a leer la novela de Hesse y a sentir lo que nunca antes había sentido al leer un libro, aquel interés, aquella emoción, aquel deseo de seguir leyendo, de comparar mi vida con la de los personajes, la manera como hacía míos sus interrogantes, como me involucraba en su trama de complejas relaciones, me di cuenta de que todo en aquel libro me hablaba por primera vez de lo mucho que encerraba el término literatura cuando uno como lector llegaba a ella sin coerción alguna, libremente, con la sola sospecha de que ahí le esperan revelaciones inusitadas.

A partir de ese momento, el interés por las obras literarias, en particular por las novelas, pasó a ocupar un lugar especial en mi vida, hasta el punto de dedicarle a su lectura días enteros y de no querer terminar la lectura de una sin no tener la siguiente en mis manos. En esos días de la euforia del descubrimiento, andaba atento a cualquier comentario de los conocedores que me sirviera de guía para seleccionar mis lecturas.

\footnotetext{
Hermann Hesse recibió el premio Nobel de literatura en 1946.
} 


\section{Falta el cine}

A la filosofía en cierta forma había llegado por mi propia cuenta, a la música y a la literatura de la forma que acabo de contar. Mi historia con el cine, me refiero al cine artístico, es un poco diferente, aquí la influencia de mi amigo no fue tan decisiva. Para cuando entré a la universidad ya sabía que el cine me cautivaba, que cuando niño, las pocas veces que pude ver una película, porque era en sala de cine y pagando por la entrada, la pasé muy bien, que era increíble poder identificarse con los diferentes personajes de las películas y de alguna manera, sentadito en una butaca, poder vivir con ellos, por empatía, aventuras extraordinarias.

En este sentido, lo que el ambiente de la universidad aportó a mi formación artística tiene que ver con lo aspectos cualitativos, dado que era frecuente ver pegados en las paredes de las diferentes facultades afiches anunciando ciclos de películas en el auditorio Abelardo Bonilla, recalcando que se trataba de lo mejor del cine. Con ver algunas de estas películas quedaba claro en uno el hecho de que el cine puede ir más allá del entretenimiento y abordar todo tipo de cuestiones, inclusive los grandes temas filosóficos y que podía hacerlo, además, artísticamente. Fue lo que comprobé el día que pude ver ahí la película El extranjero, basada en la novela del filósofo Camus (2005).

También aprendí que un buen foro al final de cada película es una oportunidad para el exorcismo de los posibles demonios que la película pueda haber dejado en uno. Porque viéndolo bien, el cine tiene su peculiar forma de decirnos sus cosas. Con eso de que nos mete en una sala, nos acomoda en un asiento que nos deja mirando solo hacia el frente y que además nos apagan la luz para que sólo nos ocupemos de lo que pasa en la pantalla, uno pasa ahí su rato como en estado hipnótico, prácticamente tragándose lo que la película va diciendo.

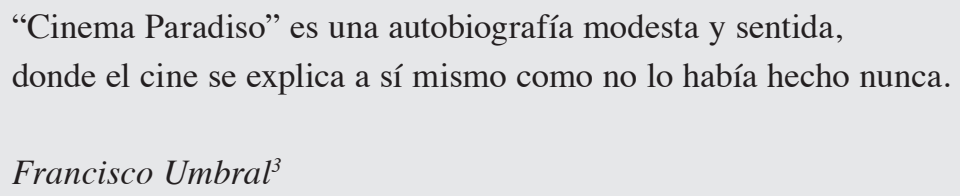

Lo cierto es que igual que me había sucedido con la música clásica y la literatura, me sucedió con el cine y de ahí en adelante cada vez que podía me metía en una de esas salas y en no pocas ocasiones la película era estimulante en algún sentido y uno salía contento con la elección hecha. Coincidió con este salto cualitativo mío en materia de cine el que por esos días se comenzara a hablar de una nueva sala de cine en San José, la Sala Garbo, orientada a dar a conocer a un público más exigente las películas que no llegaban a las salas más comerciales. Y allí pude ver, entre otras cosas, un ciclo completo de películas de Bergman.

Cuento estas cosas porque así hablo de lo que ha sido mi educación artística, la que realmente ha operado cambios importantes en mi vida. Y por lo que llevo dicho, ya puede verse que no se trata de una educación recibida en las aulas, desde la educación formal, aunque en mi escuela primaria había un poco de música y en el colegio recibiera además de música, clases de artes plásticas y de una manera muy extraña también de literatura. ¿Por qué extraña en el caso de la literatura? Porque nunca

\footnotetext{
Francisco Pérez Martínez más conocido como Francisco Umbral (Madrid, 11 de mayo de 1935 - Boadilla del Monte, Madrid, 28 de agosto de 2007), periodista, novelista, biógrafo, ensayista y poeta español.
} 
sentí que se quisiera con ella contribuir a nuestra formación artística, suponían incluso que la misma persona que explicaba la gramática y las demás cosas técnicas del idioma español podía, igualmente, hacerse cargo de los contenidos literarios del programa. Esto que todavía se sigue haciendo en las escuelas y colegios explica que aunque uno en cierta forma aprendía a escribir, nunca se le ocurría usar ese aprendizaje en escribir un poema o cuento. Algo muy parecido se puede decir de la lectura.

\section{¿Somos artistas?}

Como estoy hablando de mi educación artística, alguien podría preguntarme por los resultados obtenidos y al oír que en el caso de la música me convertí en un oyente de música clásica, que en el de la literatura en un lector de novelas y en el del cine en un espectador de películas, podría comentar que de la educación artística se esperan resultados más creativos y que a lo mejor lo mío no debería llevar ese nombre sino uno más modesto.

En este caso habría que empezar aclarando que la creatividad no es algo que solo tenga que ver con ese particular hacer de los humanos llamado arte, que el arte es sólo una expresión de la creatividad y no la creatividad misma, que los humanos hacemos otro montón de cosas más donde también está en juego la creatividad. Que ni siquiera la creatividad es un atributo privativo de los humanos, que ya a partir de ciertos niveles vitales se pueden observar conductas de los seres vivos que dejan ver una intención de influir unos en otros para los fines de la sobrevivencia; conductas donde ya hay un nivel de cognición estética.

(...) Somos la más reciente, la más flamante extravagancia de esta Tierra extraordinariamente creativa (Swimme, 1998, p. 22).

Lo otro es que aun reconociendo que la creación artística constituya un grado de creatividad especial, eso no convierte en artista solo al que con su trabajo creativo realiza determinada obra. No sé de ningún pintor, por poner un ejemplo, que pinte con la intención de guardar sus cuadros en un armario donde nadie los vea; no, el que pinta quiere decir algo con sus pinturas y decírselo a alguien, alguien de quien el pintor espera que pueda recrear su trabajo y no simplemente verlo. En su decir el artista no lo dice todo, mucho se queda en el nivel de la insinuación, del detalle sugestivo y que el destinatario se encargue desde su comprensión creadora de hacer el resto. Pero esto no lo podría hacer el destinatario si en cierta forma no fuese también artista.

\section{¿Se puede bloquear la creatividad?}

Cuando leía el libro de Bohm y Peat (1998) Ciencia, orden y creatividad: Las raíces creativas de la ciencia y la vida, en la parte donde hablan de los inconvenientes de la entronización de un paradigma, ahí me topé con esta reflexión: 
Debería quedar claro ahora que la disposición de la mente a engañar se halla estrechamente relacionada con la fragmentación y el bloqueo del juego libre y creativo. Por ejemplo, aferrarse a ideas familiares es esencialmente lo mismo que impedir a la mente el comprometerse en un libre juego creativo. Y, a su vez, es esta ausencia de libre juego creativo la que impide que la mente tenga la tensión vibrante y la energía necesarias para liberarla de la rigidez de la estructura tácita de las ideas habituales. Es más, una mente a la que se obliga a aferrarse a lo que le es conocido y que no puede realizar un juego libre está de hecho jugando sucio. Se le ha obligado a aceptar que no puede ser de otra manera. La cuestión de qué viene antes, el juego sucio o el bloqueo del juego libre es como saber qué vino antes, si el huevo o la gallina $\mathrm{y}$, por lo tanto, no tiene importancia. Son solo dos lados de un único proceso. (Bohn y Peat, 1998, pp. 63-64)

Esta y otras reflexiones igualmente provocativas del libro mencionado me han hecho recordar muchas veces la película La sociedad de los poetas muertos. El colegio que sirve de contexto a los acontecimientos que presenta esa película fue concebido

Sociedad de los poetas muertos, aquí el profesor les dice a los estudiantes:

"Cuando lean no consideren lo que el autor piensa, consideren lo que ustedes piensan”. (Half, Witt y Thomas (1989) desde un principio para que sirviera de apoyo al orden establecido, al paradigma dominante, es decir, para que su trabajo "educativo" preparara a los jóvenes para insertarse con éxito dentro de ese orden cuyas bondades se daban por sentadas. Nada más lejos, entonces, de los propósitos de esa institución que promover un ambiente de libre juego creativo como el que recomiendan Bohm y Peat (1998). No, allí se le rinde culto a la tradición, a la disciplina, al honor; todo se hace como se ha venido haciendo desde el primer día, todo está suficientemente probado y se sabe que funciona.

Entonces uno se pregunta cómo fue que contrataron al nuevo profesor sin saber lo que realmente pensaba de la institución en la que iba a trabajar; institución a la que conocía muy bien porque él mismo había estudiado ahí. Y ese profesor sabe a lo que va, él sabe que la creatividad de esos chicos ha sido bloqueada por tantos años de "educación" enajenante y que sólo mediante estrategias pedagógicas innovadoras podrá hacer de ellos gente dispuesta al libre juego creativo, capaz de enamorarse de la vida. Es por eso que en cada una de sus clases se le ve haciendo cosas diferentes, "ejercicios de liberación" los llamaría yo, como cuando los invita a que se suban en la mesa o cuando los lleva al patio a caminar "alocadamente". Claro, mientras él hace, otros lo observan, entre ellos, el director del colegio. Y lo observan con inquietud, con preocupación, como se observan esos vientos agitados que preludian un huracán. En un lugar donde la palabra cambio está prohibida en el acta fundacional del mismo.

Realmente me gusta la tesis que defiende esta película en relación con la creatividad. Cuando la ví por primera vez ya había leído el libro La filosofía de Jaspers (1966), un libro donde el autor dedica las primeras páginas a hablar del asombro como causa del filosofar, de cómo el asombro está vivo en la niñez, lo que hace de los niños filósofos por excelencia, y de cómo, con el crecimiento, ese asombro se va muriendo. Y no pude evitar la relación. Igual que nacemos filósofos nacemos poetas, me dije; e igual que se nos muere (o nos lo matan) el filósofo, se nos muere el poeta y eso es una tragedia porque nos convierte en autómatas. Todo lo que se haga, entonces, para revivir ese filósofo, ese poeta, que llevamos dentro, para desbloquearnos la creatividad, en palabras de Bohm y Peat (1998), nos hace mucho bien, tanto individual como colectivamente. 


\section{¿Y lo ecológico?}

Hablé de música, de literatura y de cine y no he mencionado el tema ecológico, esencial en este documento, por lo menos no lo he mencionado directamente. Para hacerlo voy a valerme de un hallazgo hecho por Morin $(2002$, p. 27) y que lo desarrolla en su libro La cabeza bien puesta cuando dice:

(...) El desarrollo de la aptitud para contextualizar tiende a producir el surgimiento de un pensamiento ecologizante en el sentido de que sitúa todo acontecimiento, información o conocimiento en una relación inseparable con el medio -cultural, social, económico, político y, por supuesto, natural-. No hace más que situar un acontecimiento en su contexto, incita a ver cómo éste modifica al contexto o cómo le da una luz diferente. Un pensamiento de este tipo se vuelve inseparable del pensamiento de lo complejo, pues no basta con inscribir todas las cosas y hechos en un "marco" u "horizonte". Se trata de buscar siempre las relaciones e inter-retroacciones entre todo fenómeno y su contexto, las relaciones recíprocas entre el todo y las partes: cómo una modificación local repercute sobre el todo y cómo una modificación del todo repercute sobre la partes(...).

Pues bien, toda creación artística se lleva a cabo desde un contexto, el contexto en el que vive el creador, esto es evidente. Pero además, el artista para decir sus cosas lo hace creando un contexto. Pienso en el novelista, su hacer de novelista le obliga a crear un contexto que le de verosimilitud a lo que en ese contexto nos cuenta que sucede. Los acontecimientos en una novela están interrelacionados, a veces de forma muy cercana y directa, a veces de forma lejana e indirecta, y el novelista debe dar cuenta de estas relaciones. Yo diría que también el cineasta está en la misma situación. En este sentido, un contexto mal logrado y lo que resulta es una novela mala, en un caso, y una película mala, en el otro.

Tengo frente a mí una pintura de van Gogh (1886), se trata de una pintura de un par de zapatos viejos y muy usados. Aquí la aptitud para contextualizar de que habla Morin recurre a un procedimiento diferente, casi contrario al del novelista o al del cineasta, aquí se trata de centrarse en el detalle, en la parte, en los zapatos. ¿Y el todo del que esos zapatos forman parte? ¿Y la persona que calza esos zapatos? Ese todo, esa persona, están holográficamente en esos zapatos. El autor quería hablarnos de ese todo, de esa persona, de su pobreza, de lo dura que es su vida, posiblemente también de su tristeza y lo hizo dejándonos ver sus zapatos. Y lo logró, esos zapatos conmueven.

Quiere decir que de nuestro trato diario con el arte, en mi caso, de mis lecturas literarias, de mi ver películas y escuchar música, no sólo se gana lo que ya tanto se ha dicho en relación con el impacto humanizador del mismo, sino que debido a este carácter contextualizante del arte, se gana también en que nos ayuda a desarrollar el surgimiento de un pensamiento ecologizante, es decir, nos ayuda a superar la visión fragmentaria y mecanicista que del mundo y de la vida nos ha dado un paradigma cuyo predominio se remonta a los tiempos de Descartes y de Newton y que hoy nos tiene, como civilización, al borde del colapso total. 
URL: http://www.una.ac.cr/educare

\section{Referencias bibliográficas}

Bohm, D. y Peat, D. (1998). Ciencia, orden y creatividad. Las raíces creativas de la ciencia y la vida ( $2^{\mathrm{a}}$ ed.). Barcelona: Editorial Kairós.

Camus, A. (2005). El extranjero (12ª impresión). España: Emecé.

Half, S., Witt, J. y Thomas, T. (Productores) y Weir, M. (1989). La sociedad de los poetas muertos [Película]. Estados Unidos: Touchstone Pictures

Hesse, H. (1978). Demian. Germany: Compañía General de Ediciones México.

Jaspers, K. (1966). La filosofía. México: FCE.

Morin, E. (2002). La cabeza bien puesta. Buenos Aires: Nueva Visión.

Swimme, B. (1998). El universo es un dragón verde. Un relato cósmico de la creaión (2a ed.). Santiago: Sello Azul.

Umbral, F. (2008). Comentario. Fotolog. Recuperado de http://www.fotolog.com/kens0ul/26332582

van Gogh, V. (1886), Un par de zapatos. Recuperado de http://www.reproarte.com/cuadro/ Vincent+van Gogh/Un-par+de+zapatos/5128.html 